\title{
DMPK dosage alterations result in atrioventricular conduction abnormalities in a mouse myotonic dystrophy model
}

\author{
Charles I. Berul, ${ }^{1}$ Colin T. Maguire, ${ }^{1}$ Mark J. Aronovitz, ${ }^{2}$ Jessica Greenwood, ${ }^{3}$ Carol Miller, ${ }^{4}$ \\ Josef Gehrmann, ${ }^{1}$ David Housman, ${ }^{3}$ Michael E. Mendelsohn, ${ }^{2}$ and Sita Reddy ${ }^{4}$ \\ ${ }^{1}$ Department of Cardiology, Children's Hospital, Harvard Medical School, Boston, Massachusetts 02115, USA \\ ${ }^{2}$ Molecular Cardiology Research Institute, Department of Cardiology, Tufts-New England Medical Center, Boston, Massachusetts 02111, USA \\ ${ }^{3}$ Center for Cancer Research, Massachusetts Institute of Technology, Cambridge, Massachusetts 02139, USA \\ ${ }^{4}$ Institute for Genetic Medicine, University of Southern California School of Medicine, Los Angeles, California 90033 USA
}

Address correspondence to: C.I. Berul, Department of Cardiology, Children's Hospital, 300 Longwood Avenue, Boston, Massachusetts 02115, USA. Phone: (617) 355-6432; Fax: (617) 355-7513; E-mail: berul@cardio.tch.harvard.edu

Received for publication September 28, 1998, and accepted in revised form December 22, 1998

Myotonic dystrophy (DM) is the most common form of muscular dystrophy and is caused by expansion of a CTG trinucleotide repeat on human chromosome 19. Patients with DM develop atrioventricular conduction disturbances, the principal cardiac manifestation of this disease. The etiology of the pathophysiological changes observed in DM has yet to be resolved. Haploinsufficiency of myotonic dystrophy protein kinase (DMPK), DM locus-associated homeodomain protein (DMAHP) and/or titration of RNA-binding proteins by expanded CUG sequences have been hypothesized to underlie the multi-system defects observed in DM. Using an in vivo murine electrophysiology study, we show that cardiac conduction is exquisitely sensitive to DMPK gene dosage. $\mathrm{DMPK}^{-/-}$mice develop cardiac conduction defects which include first-, second-, and third-degree atrioventricular $(\mathrm{A}-\mathrm{V})$ block. Our results demonstrate that the $\mathrm{A}-\mathrm{V}$ node and the His-Purkinje regions of the conduction system are specifically compromised by DMPK loss. Importantly, $\mathrm{DMPK}^{+/-}$mice develop firstdegree heart block, a conduction defect strikingly similar to that observed in DM patients. These results demonstrate that DMPK dosage is a critical element modulating cardiac conduction integrity and conclusively link haploinsufficiency of DMPK with cardiac disease in myotonic dystrophy.

J. Clin. Invest. 103:R1-R7 (1999).

\section{Introduction}

The disorders of skeletal muscle and cardiac function observed in myotonic dystrophy (DM) occur as a consequence of a CTG repeat expansion $(1,2)$ located in the $3^{\prime}$ untranslated region of a protein kinase, myotonic dystrophy protein kinase (DMPK; 3,4 ), on chromosome 19q13.3. The molecular mechanisms by which expanded CTG sequences produce DM pathophysiology remain unresolved, though three models prevail. First, partial loss of DMPK resulting as a consequence of nuclear retention of the mutant DMPK mRNA may contribute to DM (5-8). Second, decreased transcription of a neighboring homeodomain-encoding gene, DMAHP, occurring possibly due to altered chromatin structure near the CTG expansion, may play a role in DM
$(9,10)$. Lastly, transdominant effects associated with expression of expanded CUG repeats and modulation of splicesite recognition may contribute to DM pathology (11-13).

The primary clinical cardiac manifestation in DM is the development of conduction disturbances, with progressive atrioventricular $(\mathrm{A}-\mathrm{V})$ block and bradycardia. Prolonged A-V conduction (first-degree $\mathrm{A}-\mathrm{V}$ block) is common, and higher-grade $\mathrm{A}-\mathrm{V}$ block is a significant cause of death (14-17). The His-Purkinje system may also be affected, with bundle branch block and intraventricular conduction delay $(18,19)$.

To test the hypothesis that partial DMPK loss contributes to DM pathology, we developed a mouse strain lacking functional DMPK $\left(\mathrm{DMPK}^{-/}\right)$. We have shown that $\mathrm{DMPK}^{-/-}$mice develop late-onset skeletal myopathy as a consequence of abnormal excitation/contraction coupling (20). In this study we demonstrate that DMPK dosage modulates cardiac conduction. On electrocardiogram (ECG), a prolonged $\mathrm{P}-\mathrm{R}$ interval (first-degree $\mathrm{A}-\mathrm{V}$ block) was present in adult $\mathrm{DMPK}^{-/-}$mice compared to wild-type controls. Electrophysiological evaluation of $\mathrm{DMPK}^{-1-}$ mice demonstrated more serious conduction disturbances including second and third-degree $\mathrm{A}-\mathrm{V}$ block. Adult $\mathrm{DMPK}^{+/-}$mice also exhibited firstdegree $\mathrm{A}-\mathrm{V}$ block similar to DMPK- ${ }^{-1}$ mice. Thus, heterozygous animals have a quantifiable cardiac phenotype reminiscent of DM patients. Our results show that DMPK gene disruption causes $A-V$ conduction abnormalities in both homozygous and heterozygous DMPK-deficient mice, and support loss of DMPK as playing a dominant role in the characteristic DM cardiac phenotype.

\section{Methods}

Animal care. A total of 27 male and 20 female adult $129 /$ BS strain mice were studied. The mean age was $63.9 \pm 21$ weeks, with no differences between genotypes. The average weight was $37.7 \pm 9$ grams. Another 18 young mice were studied to assess age-related alterations in conduction properties. Death occurred in 6 animals due to procedural complications. Mice were housed in a diurnal facility, in compliance with the American Association for the Accreditation of Laboratory Animal Care and each center's Institutional Animal Care and Use Committee. Mice were anesthetized with intraperitoneal ketamine hydrochloride and pentobarbital $(0.033 \mathrm{mg} / \mathrm{gm}$ each $)$. 
Electrocardiography and electrophysiology stud$i e s$. The mouse electrophysiological study methodology has been previously described in detail $(21,22)$. A multilead surface electrocardiogram (ECG) was obtained and both epicardial and endocardial surgical techniques were performed. The epicardial approach involved a midline sternotomy for placement of pacing wires on each heart chamber (21). An octapolar mouse electrophysiology catheter (NuMED, Inc., Hopkinton, New York, USA) was placed via jugular vein for pacing and endocardial electrogram recording (22-24). The catheter has precise interelectrode distances, allowing the proximal 2 electrode pairs to pace and record the right atrium, while the distal electrodes lie in the right ventricle for stimulation and signal acquisition. Cardiac rhythm and respirations were monitored, ECG intervals calculated, and standard pacing protocols used to determine the electrophysiologic parameters (21-25). Pharmacological autonomic manipulations were performed using intravenous isoproterenol $(1-3 \mathrm{ng} / \mathrm{gm})$ and atropine $(1 \mathrm{ng} / \mathrm{gm})$.

Ambulatory electrocardiogram telemetry. A subset of $3 \mathrm{DMPK}^{-/,}, \mathrm{DMPK}^{+/-}$, and $\mathrm{DMPK}^{+/+}$mice underwent ambulatory ECG recordings using implantable radiotransmitters (DataSciences International, St. Paul, Minnesota, USA). Following a 48-h stabilization period, ECG recordings were acquired for $5 \pm 3$ days, including periods of rest and exertion. Each animal underwent a graded exercise test, using a swimming protocol. The mice were placed in a warm bath, and swam for incrementally longer intervals each day, increasing to $9 \mathrm{~min}$ on day 10 of exercise. Custom software was designed for automated acquisition, analysis, and computation of heart rate variability parameters. Sympathetic and parasympathetic influences on heart rate regulation were quantified by frequency domain power spectral techniques.

Data acquisition and analysis. Surface ECGs and electrogram recordings were acquired on a multichannel amplifier and converted to a digital signal for analysis (MacLab System, AD Instruments, Milford, Massachusetts, USA). Pacing and programmed stimulation was performed with a Bloom DTU-201 stimulator (Fischer Imaging Corp., Denver, Colorado, USA), modified to enable the rapid pacing intervals necessary in mice.

Statistical analysis. All continuous variables, such as ECG intervals and cardiac conduction properties, were compared to genderand age-matched controls, with data presented as the mean \pm 1 standard deviation. Statistical analysis included the 2-tailed Student's $t$ test; analysis of variance (ANOVA), with Scheffé subgroup testing when appropriate; and analysis of interobserver variability. A $P$ value of $<0.05$ was considered statistically significant.

\section{Results}

Adult $\mathrm{DMPK}^{+/-}$and $\mathrm{DMPK} \mathrm{K}^{-/-}$mice exhibit first-degree $A-V$ block. ECG analysis was obtained on mature $\mathrm{DMPK}^{-/-}$mice ( $n=$ 17) and wild-type control animals $(n=$ 17) at 6-7 months and again at 17-19 months of age. Additionally, to assess the effects of DMPK haploinsufficiency, $10 \mathrm{DMPK}^{+/-}$animals were studied at 16-19 months of age. The mean sinus cycle length (beat-to-beat heart rate), Pwave duration (atrial conduction time), $\mathrm{P}-\mathrm{R}$ interval (atrial and A-V nodal conduction time), QRS interval (ventricular depolarization time), J-T interval (ventricular repolarization time), and $\mathrm{Q}-\mathrm{T}$ interval (surrogate of action potential duration) were measured (Table 1). The average resting sinus cycle length was $156.9 \pm 40.3$ milliseconds (heart rate $404.8 \pm 94.6$ beats per minute $[\mathrm{bpm}])$ in $\mathrm{DMPK}^{-/-}$mice, $152 \pm$ 34.3 milliseconds (heart rate $413.1 \pm$ $93.7 \mathrm{bpm}$ ) in heterozygotes, and 148.2 \pm 30.8 milliseconds (heart rate $421.7 \pm$ $88.4 \mathrm{bpm}$ in wild-type controls. $(P>$ 0.05 for all measurements.) Normal sinus rhythm was present in all three groups, implying that sinoatrial node function was not impaired. Both the $\mathrm{DMPK}^{-/-}$and the $\mathrm{DMPK}^{+/-}$mice had similarly prolonged atrioventricular conduction times when compared to the wild-type controls. On ECG, a prolonged $\mathrm{P}-\mathrm{R}$ interval was seen in all adult homozygous $\mathrm{DMPK}^{-/}$mice (mean $\pm \mathrm{SD}=48 \pm 7$ milliseconds) and in all 10 heterozygous $\mathrm{DMPK}^{+/-}$mice (mean $\mathrm{P}-\mathrm{R}=48 \pm 8$ milliseconds), compared with wild-type mice (mean $\mathrm{P}-\mathrm{R}=$ $34 \pm 5$ milliseconds) (Fig. 1a). $(P<0.001$ for all measurements.) Basal heart rates (reflecting sinus node automaticity) and other ECG intervals (QRS, J-T, Q-T, Q-Tc, and J-Tc [c indicates interval corrected for heart rate]) in DMPKmutant homozygotes and heterozygotes were not significantly different from wild-type controls (Table 1). Intraventricular conduction abnormalities, appreciable on the ECG as either right or left bundle branch block or nonspecific intraventricular conduction delay, were present in $22 \%$ of mutant mice, but were also apparent in $12 \%$ of wildtype mice $(P=0.07)$. DMPK-deficient mice had $\mathrm{P}-\mathrm{R}$ prolongation with a normal P-wave duration and QRS interval, indicating $\mathrm{A}-\mathrm{V}$ node dysfunction. A lack of conduction delay through the working atrial muscle and ventricular myocardium suggests specific action at the level of the specialized conduction tissue.

$D M P K^{-1-}$ mice manifest severe $A-V$ conduction disturbances including second-and third-degree A-V block. Sinus node, atrial, $\mathrm{A}-\mathrm{V}$ and ventricular conduction properties and refractoriness were further studied in $\mathrm{DMPK}^{-/-}, \mathrm{DMPK}^{+/-}$, and $\mathrm{DMPK}^{+/+}$mice using an in vivo electrophysiologic study (Table 2). Rate-corrected sinus node recovery time (CSNRT) was evaluated for the indirect determination of sinus node function. CSNRT measurements were more varied among $\mathrm{DMPK}^{-/-}$mice; however, the mean CSNRT was similar among all three groups $(P>0.05)$, implying normal intrinsic sinus node function. Programmed atrial stimulation was performed to assess A-V nodal physiology (Fig. 2). $\mathrm{DMPK}^{-/-}$mice manifested more severe $\mathrm{A}-\mathrm{V}$ conduction disturbances during atrial pacing (Fig. 2a). Five of 17 $\mathrm{DMPK}^{-/-}$mice had second-degree A-V block (Fig. $2 b$ ), and 2 of $17 \mathrm{DMPK}^{-/-}$ mice had third-degree A-V block (Fig. 2c). None of the $\mathrm{DMPK}^{+/-}$or $\mathrm{DMPK}^{+/+}$ mice had any higher-grade atrial or $\mathrm{A}-\mathrm{V}$ dysfunction (Table 3 ). These results show that DMPK loss results in A-V conduction delay and demonstrate a critical role for DMPK in $\mathrm{A}-\mathrm{V}$ node function.

The severity of conduction disturbances increases as a function of age in $D M P K^{-1}$ mice. There were no significant differences in conduction parameters on surface ECG or intracardiac recordings

\section{Table 1}

Electrocardiographic data summary

\begin{tabular}{lcccccc}
\hline & $\mathrm{P}-\mathrm{R}$ & $\mathrm{QRS}$ & $\mathrm{J}-\mathrm{T}$ & $\mathrm{Q}-\mathrm{T}$ & $\mathrm{Q}-\mathrm{Tc}$ & $\mathrm{J}-\mathrm{Tc}$ \\
$\mathrm{DMPK}^{+/+}$ & $34.1 \pm 4.75$ & $29.9 \pm 6.14$ & $52 \pm 15$ & $82 \pm 15$ & $214.3 \pm 25.6$ & $136.0 \pm 30.69$ \\
$\mathrm{DMPK}^{+/-}$ & $48.0 \pm 7.8$ & $33.6 \pm 5.8$ & $50 \pm 9.4$ & $84 \pm 11$ & $217 \pm 23.1$ & $130.4 \pm 22.15$ \\
DMPK $^{-/-}$ & $48.2 \pm 7.4$ & $29.1 \pm 6.59$ & $52 \pm 16$ & $81 \pm 17$ & $205.2 \pm 24.5$ & $130.6 \pm 29.26$
\end{tabular}

The resting surface ECG intervals for wild-type $\left(\mathrm{DMPK}^{+/+}\right)$, heterozygote $\left(\mathrm{DMPK}^{+/-}\right)$, and homozygote $\left(\mathrm{DMPK}^{-/-}\right)$ mice are tabulated. The $\mathrm{P}-\mathrm{R}$ interval was longer in both $\mathrm{DMPK}^{+/-}$and $\mathrm{DMPK}^{-/-}$mice, compared with $\mathrm{DMPK}^{+/+}$ controls. The QRS, J-T, Q-T, and rate-corrected Q-T (QTc) and J-T (J-Tc) were not significantly different between groups. $E C G$, electrocardiogram; $D M P K$, myotonic dystrophy protein kinase. 
a

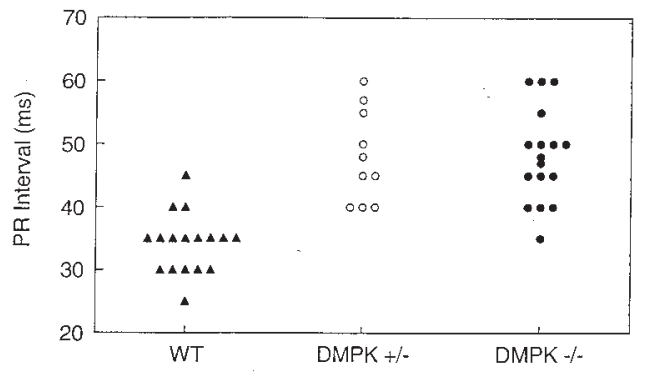

$\boldsymbol{b}$

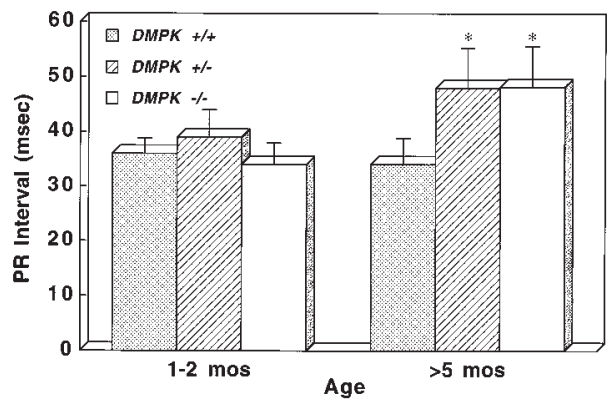

Figure 1

PR intervals of DMPK-mutant and wild-type mice. (a) Scatter diagram of individual P-R intervals on resting electrocardiograms from mature homozygote $\mathrm{DMPK}^{-/-}$, heterozygote $\mathrm{DMPK}^{+/-}$, and wild-type $\mathrm{DMPK}^{+/+}$mice. The majority of adult mutant mice had a P-R interval > 35 ms, whereas the majority of wild-type mice had a P-R interval $\leq 35 \mathrm{~ms}$. The mean $\mathrm{P}-\mathrm{R}$ interval was significantly longer in both heterozygote and homozygote adult mice, compared with control mice $(P<0.05)$. (b) Mean $\left( \pm\right.$ standard deviation) P-R interval (in ms) from two distinct age groups of DMPK ${ }^{-/}$, DMPK ${ }^{+/-}$, and $\mathrm{DMPK}^{+/+}$mice. There was no significant difference in mean P-R interval among the 1-2-month-old mice. The DMPK-deficient mice over 5 months old had a significantly prolonged mean P-R duration. WT, wild type.

among the younger (1-2-month-old) $\mathrm{DMPK}^{-/-}, \mathrm{DMPK}^{+/}$, and $\mathrm{DMPK}^{+/+}$mice. The mean $\mathrm{P}-\mathrm{R}$ interval was similar in each genotype (see Fig. 1b). There was a trend towards an increase in $\mathrm{P}-\mathrm{R}$ intervals with age, such that $\mathrm{P}-\mathrm{R}$ intervals greater than 50 milliseconds were not observed in the 6-month-old DMPK ${ }^{-/-}$ mice, and manifested only at 16-17 months of age in $\mathrm{DMPK}^{-/}$mice. Additionally, second- and third-degree heart block occurred at a higher frequency in 16-17-month-olds and primarily in mice with a $\mathrm{P}-\mathrm{R}$ interval $\geq 45$ milliseconds. Thus, the P-R duration might be used to predict the occurrence of more serious $\mathrm{A}-\mathrm{V}$ conduction disorders over time in these mice. This developmental progression of A-V block and the correlation of severe conduction disorders with the length of the P-R interval is reminiscent of DM patients.

Ambulation and exercise testing did not lead to an increase in conduction disorders. Implantable telemetry ECG recorders were surgically placed in three mice from each group and ECG tracings obtained at rest and during exercise. During monitoring, prolonged $\mathrm{P}-\mathrm{R}$ intervals were clearly evident in the homozygous and heterozygous mice (Fig. 2d). However, there was no further progression of higher-grade A-V block noted during rest, ambulation, or graded exercise testing. None of the animals had any documented ectopy, arrhythmias or sudden death during exercise. The telemetered mean heart rate and heart rate variability parameters were statistically similar among all three genotypes (Table 4).

Neither sympatholytic nor cholinergic effects are primarily responsible for progressive A-V block in DMPK mutant mice. Programmed stimulation and pacing protocols were performed at baseline and with sympathomimetic stimulation. Central isoproterenol (1-3 ng/gm) was administered to a subgroup of 11 $\mathrm{DMPK}^{+/-}$or $\mathrm{DMPK}^{-/-}$mice, and control mice. This treatment increased heart rates $20-25 \%$, shortened conduction intervals, and reduced refractoriness. However, catecholaminergic stimula- tion did not positively or negatively affect $\mathrm{A}-\mathrm{V}$ conduction parameters in DMPK-deficient mice differentially compared with controls. These results indicate that sympatholytic effects are not directly implicated in the A-V block seen in DMPK mutant mice. Following isoproterenol, the mice were administered a single dose of intravenous atropine $(1 \mathrm{ng} / \mathrm{gm})$. This shortened sinus cycle length by $14 \pm 6 \%$, without changing P-R duration or significantly shortening atrioventricular conduction times measured during atrial pacing. This data shows a lack of anticholinergic reversal of $\mathrm{A}-\mathrm{V}$ block, and implies that delayed $\mathrm{A}-\mathrm{V}$ conduction in DMPKdeficient mice is not secondary to vagal actions.

Gross structural differences were not observed in DMPK $\mathrm{K}^{+/-}$and $D M P K^{-/-}$hearts. Histological cardiac evaluation was performed on serial sections, with particular focus on the A-V node. Sections were stained with hematoxylin-eosin and Gomori trichrome to determine if structural alterations and/or increased

Table 2

Electrophysiologic data summary

\begin{tabular}{lcccccccc}
\hline & SNRT & CSNRT & AP WENK & AP 2:1 & AVERP & AERP & MIN VAC & VERP \\
DMPK $^{+/+}$ & $152.1 \pm 57.8$ & $15.7 \pm 15.4$ & $73.3 \pm 16.3$ & $60 \pm 14.1$ & $53 \pm 19.7$ & $48 \pm 14.8$ & $91 \pm 18.9$ & $63 \pm 7.6$ \\
DMPK $^{+/-}$ & $226.9 \pm 67.4$ & $33.8 \pm 35.4$ & $103.8 \pm 16$ & $86.2 \pm 15.1$ & $62 \pm 8.3$ & $40 \pm 10$ & $112 \pm 20$ & $66 \pm 8.9$ \\
DMPK $^{-/-}$ & $221.2 \pm 165$ & $66.3 \pm 110.8$ & $88.6 \pm 35.5$ & $77.3 \pm 32.9$ & $60 \pm 12$ & $54 \pm 8.9$ & $98.7 \pm 24.7$ & $59 \pm 31.1$ \\
\hline
\end{tabular}

The intracardiac electrophysiological parameters are summarized for wild-type (DMPK ${ }^{+/+}$), heterozygote (DMPK ${ }^{+/-}$), and homozygote (DMPK ${ }^{-/-}$) mice. SNRT was measured following 15 seconds of atrial pacing at cycle length $100 \mathrm{~ms}$, as the point from the last paced atrial electrogram to the first return spontaneous sinus beat. CSNRT was calculated as SNRT minus the sinus cycle length. AP WENK and AP 2:1 were measured. AVERP and AERP are maximum non-conducted coupling intervals during programmed atrial stimulation. MIN VAC was assessed as the minimum ventricular pacing cycles conducting 1:1 to the atrium. VERP was determined by programmed ventricular stimulation as the maximum coupling interval not depolarizing the ventricle. SNRT, sinus node recovery time; CSNRT, rate-corrected sinus node recovery time; $A P$ WENK, maximum atrial-paced cycle length causing Wenckebach-type atrioventricular block; $A P$ 2:1, maximum cycle length during decremental burst atrial pacing which conducts every other beat; $A-V$, atrioventricular; $A V E R P$, effective refractory period of the $\mathrm{A}-\mathrm{V}$ node-His-Purkinje system; $A E R P$, effective refractory period of the atrium; $M I N V A C$, retrograde ventriculoatrial conduction; $V E R P$, ventricular effective refractory period. 


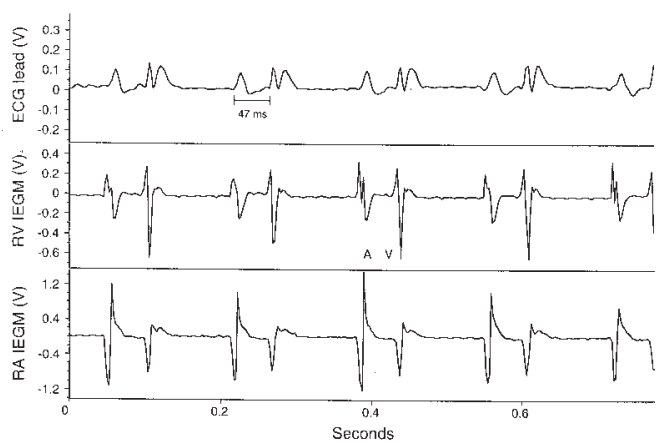

$\boldsymbol{C}$

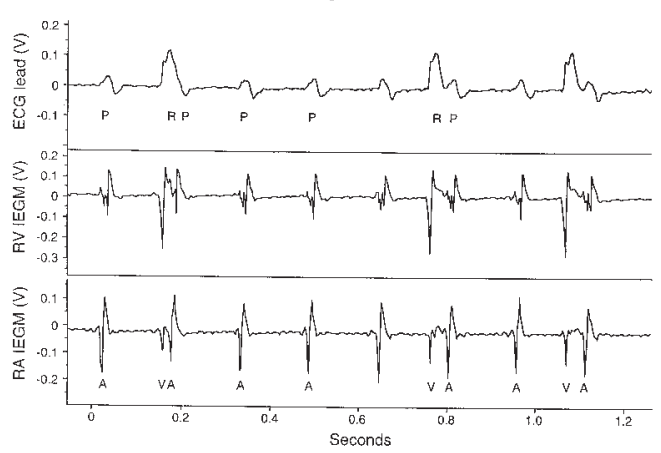

$b$ Second-degree A-V block

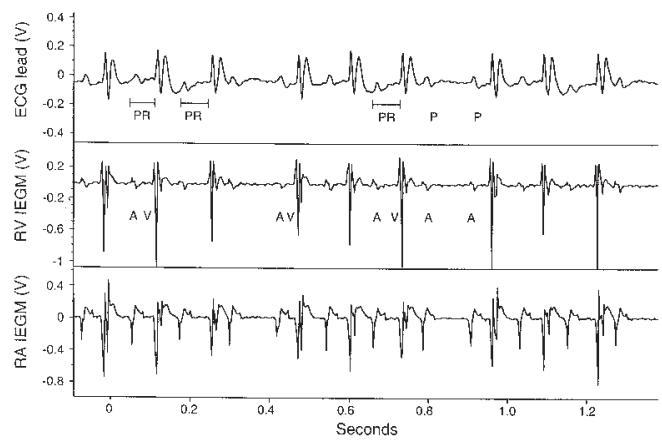

$d$

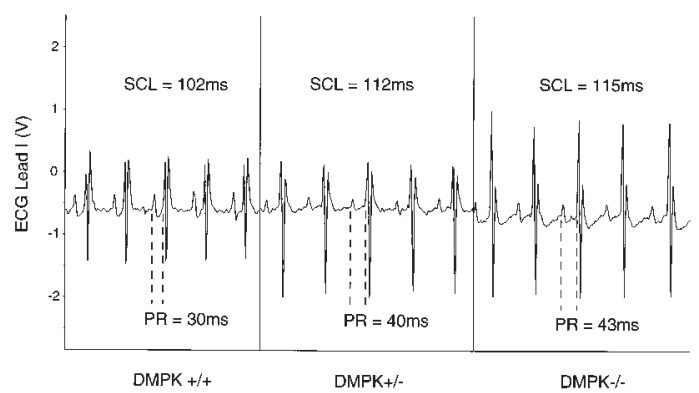

Figure 2

Selected examples of ECG and intracardiac electrogram tracings from DMPK-/- mice with varying degrees of atrioventricular (A-V) block. (a) Firstdegree A-V block. The P-R interval on ECG is prolonged to $47 \mathrm{~ms}$, coincident with a long $\mathrm{A}-\mathrm{V}$ interval on intracardiac recordings from right atrium and ventricle. (b) An example of Mobitz type I second-degree A-V block (Wenckebach phenomenon) in a DMPK-/- mouse, with gradual P-R prolongation on surface ECG and $\mathrm{A}-\mathrm{V}$ prolongation on intracardiac electrograms on each successive cycle until the atrial impulse is not conducted to the ventricle. (c) An example of third degree A-V block in a DMPK ${ }^{-/-}$mouse, with complete dissociation of the P waves from the QRS complexes. (d) Representative composite telemetered ECG samples from 3 different mice during unrestrained, unanesthetized ambulation. (a) A control DMPK ${ }^{+/+}$ mouse has an SCL of $102 \mathrm{~ms}$ and a P-R interval of $30 \mathrm{~ms}$ on the frontal ECG lead. (b) An example of a telemetered ECG from a DMPK ${ }^{+/-}$mouse, with an SCL of $112 \mathrm{~ms}$ and a P-R interval of $40 \mathrm{~ms}$. (c) A tracing from a DMPK-- mouse, with an SCL of $115 \mathrm{~ms}$ and a P-R interval of $43 \mathrm{~ms}$. IEGM, intracardiac electrogram; $R A$, right atrium; $R V$, right ventricle; $S C L$, sinus cyle length.

fibrosis could account for the conduction defects. No notable increase in either fibrosis or atrophy was detected in working myocardium or conduction system tissue, suggesting that functional deficits associated with DMPK loss and/or structural changes of the conduction system, rather than myocardial tissue changes, may underlie the observed conduction defects. Echocardiographic assessment demonstrated no differences among the three genotypes in cardiac function, chamber dimensions, wall thickness, or ventricular shortening.

\section{Discussion}

The presented work demonstrates that DMPK-deficient mice have distinct cardiac electrophysiological abnormalities specifically affecting atrioventricular conduction. The degree of $\mathrm{P}-\mathrm{R}$ prolongation on ECG is similar between mice heterozygous and homozygous for the DMPK mutation. However, $\mathrm{DMPK}^{-/}$mice display more severe disturbances of $\mathrm{A}-\mathrm{V}$ conduction during electrophysiologic testing. These results indicate that cardiac conduction is sensitive to DMPK dosage and link haploinsufficiency of DMPK with atrioventricular conduction disturbances, which are the predominant feature of cardiac disease in DM. This murine DMPK homologue has a high degree of amino acid homology with DMPK in humans, making it a useful model for studying the cardiac pathophysiology of DMPK inactivation (20).

Abnormal impulse propagation in DMPK-mutant mice may reflect changes in the magnitude of the depolarizing current and/or alterations in the geometry of cell-cell electrical connections. As neither fibrosis nor gross changes in cardiac anatomy were detected, functional alterations in impulse propagation may be the pri- mary event underlying the conduction disturbances. These data do not rule out subtle changes in cell-cell communication occurring as a consequence of structural changes in the conduction system, alteration of gap junctions, or connexin isoform distribution.

In this study, we show that impulse generation and sinus node automaticity is unaltered by DMPK loss as both heart rate and CSNRT were normal in DMPK mutant mice. Conversely, A-V

Table 3

High-grade atrioventricular block

$\begin{array}{ccc} & \begin{array}{c}\text { Second-degree } \\ \text { A-V block }\end{array} & \begin{array}{c}\text { Third-degree } \\ \text { A-V block }\end{array} \\ \mathrm{DMPK}^{+/+} & 0 & 0 \\ \mathrm{DMPK}^{+/-} & 0 & 0 \\ \mathrm{DMPK}^{-/-} & 5 / 7 & 2 / 17\end{array}$

The murine corollary of first-degree A-V block was seen in the homozygote and heterozygote DMPK mice. Higher grades of $\mathrm{A}-\mathrm{V}$ block were seen only in $\mathrm{DMPK}^{-/-}$mice. 
node function was found to be sensitive to DMPK dosage as both the $\mathrm{DMPK}^{-/}$ and $\mathrm{DMPK}^{+/}$mice exhibited prolongation of the $\mathrm{P}-\mathrm{R}$ interval in conjunction with a normal P-wave duration and QRS interval. Further abnormalities of the A-V nodal-His-Purkinje system may lead to the more severe $A-V$ disturbances observed in $\mathrm{DMPK}^{-/-}$mice upon atrial pacing.

As the $\mathrm{A}-\mathrm{V}$ node is a slow-conducting, calcium-channel dependent tissue, it is possible that calcium current $\left(\mathrm{I}_{\mathrm{Ca}}\right)$ inhibition could contribute to the prolonged A-V conduction time in DMPK mutant mice. These results are consistent with our previous study of $\mathrm{DMPK}^{-/}$skeletal muscle abnormalities in excitation-contraction coupling occurring downstream of calcium efflux from the sarcoplasmic reticulum, leading to a $30-50 \%$ decrease in twitch and tetanic force generation (20). Benders et al. have demonstrated that the amplitude of calcium responses in $\mathrm{DMPK}^{-/}$cultured myotubes are reduced by $40 \%$ compared to controls (26). Similar reductions in $\mathrm{I}_{\mathrm{Ca}}$ activation or amplitude in the $\mathrm{A}-\mathrm{V}$ node could contribute to abnormally slow impulse propagation. Less likely is the possibility that alterations in sodium channel function in the fast-conducting tissues of the A-V node and of the His-Purkinje system contribute to the conduction abnormalities, because cardiac voltagegated sodium channel function is not modulated by DMPK activity when assayed in Xenopus oocytes (27). Abnormalities in potassium channel function are also unlikely to significantly contribute to the conduction disturbances, as repolarization was found to occur normally as reflected by normal J-T intervals and lack of repolarization delay or heterogeneity (28).

DMPK loss may alter the phosphorylation status of ion channels, particularly calcium currents, and consequently modulate ion homeostasis in the specialized conduction system. Timchenko et al. have demonstrated that recombinant DMPK alters the phosphorylation status of dihydropyridine receptors in vitro, with activation of the $\beta$ subunit (29). The profile of channel function affected by DMPK loss is currently being evaluated in $\mathrm{DMPK}^{-/-}$mice both by patch-clamp single cell analysis and by studying the treatment of heart block with drugs which modulate specific ion channel functions. A second

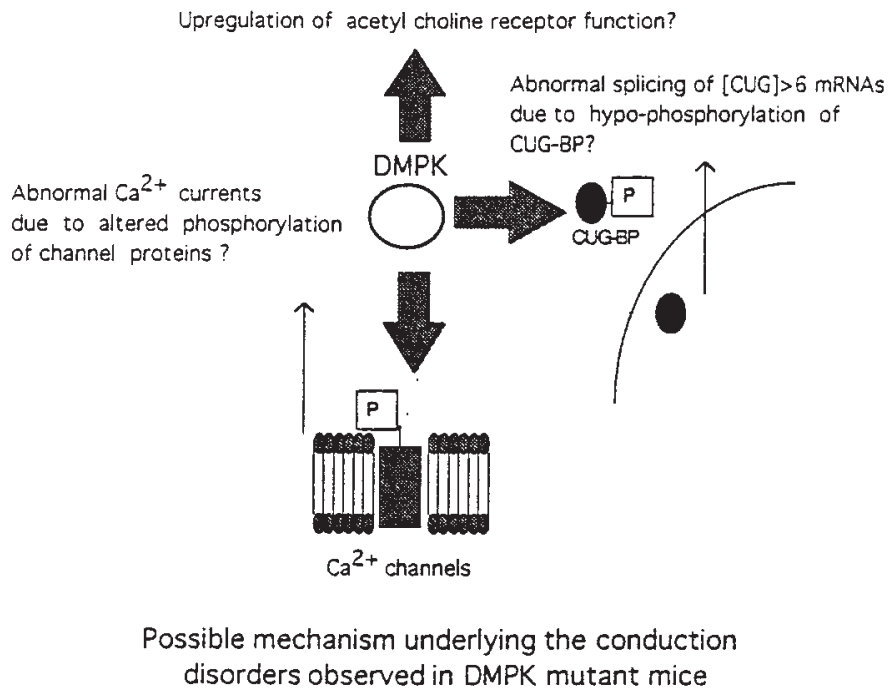

Figure 3

Schematic mechanistic model of DMPK mouse $A-V$ conduction abnormalities. The diagram illustrates the possible ionic and cellular interactions and effects of DMPK deficiency on the modulation of cardiac conduction.

DMPK substrate which may play a role is a CUG repeat binding protein (CUGBP) which has been shown to modulate splice-site recognition $(13,30)$. It has been previously demonstrated that CUG-BP is a splicing factor that is directly phosphorylated by DMPK, and that both DM patients and DMPK ${ }^{-/}$ mice accumulate hypophosphorylated CUG-BP in cardiac cell nuclei (30). It is unclear whether nuclear accumulation of hypophosphorylated CUG-BP results in abnormal splicing in $\mathrm{DMPK}^{-/-}$mice. Alterations in splice-site recognition, if present in $\mathrm{DMPK}^{+/-}$and $\mathrm{DMPK}^{-/-}$mice, may contribute to the

observed conduction disturbances. Upregulation of acetylcholine receptor function, either directly or indirectly, by DMPK deficiency may also result in prolongation of $\mathrm{A}-\mathrm{V}$ conduction or higher-grade A-V block. DMPK has been shown to localize at the neuromuscular junction (31), supporting a role for cholinergic receptor modulation. Thus, our data is consistent with DMPK being part of a tightly regulated signaling pathway in which small changes in DMPK dosage result in underphosphorylation of key targets (Fig. 3), resulting in both decreased skeletal force generation and in specific

\section{Table 4}

Heart rate variability parameters

\begin{tabular}{lcccccc}
\hline & $\begin{array}{c}\mathrm{DMPK}^{-/-} \\
n=21\end{array}$ & $\begin{array}{c}\mathrm{DMPK}^{+/-} \\
n=20\end{array}$ & $\begin{array}{c}\mathrm{DMPK}^{+/+} \\
n=17\end{array}$ & $\begin{array}{c}P \\
-/- \text { vs. }+/+\end{array}$ & $\begin{array}{c}P \\
-/- \text { vs. }+/-\end{array}$ & $\begin{array}{c}P \\
+/- \text { vs. }+/+\end{array}$ \\
RR mean (ms) & 108 & 110 & 106 & 0.7 & 0.7 & 0.4 \\
RR median (ms) & 108 & 110 & 106 & 0.7 & 0.7 & 0.4 \\
HR (bpm) & 572 & 555 & 569 & 0.9 & 0.6 & 0.5 \\
PLF $\left(\mathrm{ms}^{2}\right)$ & 87.1 & 259.7 & 20.6 & 0.1 & 0.5 & 0.3 \\
PHF $\left(\mathrm{ms}^{2}\right)$ & 74.3 & 97.3 & 25.9 & 0.1 & 0.8 & 0.3 \\
PLFn & 0.38 & 0.46 & 0.45 & 0.5 & 0.3 & 0.6 \\
PHFn & 0.62 & 0.54 & 0.55 & 0.7 & 0.5 & 0.7 \\
PLFn:PHFn & 0.61 & 0.85 & 0.82 & 0.8 & 0.3 & 0.4
\end{tabular}

Frequency domain methods were used to quantify sympathetic and parasympathetic influences on heart rate variability. The mean and median RR intervals (in $\mathrm{ms}$ ) and conversion to heart rate (bpm) were similar among $\mathrm{DMPK}^{-/}, \mathrm{DMPK}^{+/}$, and $\mathrm{DMPK}^{+/+}$groups. PLF was defined as a range of 0.4-1.5 Hz bandwidth, and PHF as a range of 1.5-4 Hz. Normalized units PLFn and PHFn were obtained as fractional equivalents of total power minus very low frequency power. The ratio PLFn:PHFn is given to determine relative power spectra. There were no significant differences in any of the heart rate variability parameters measured among the 3 genotypes during telemetered ambulatory drug-free ECG acquisition. $R R$, cycle length between $\mathrm{R}$ waves. $H R(\mathrm{bpm})$, heart rate in beats per minute; $P L F$, low-frequency power; $P H F$, high-frequency power. 
cardiac conduction disorders.

These findings were compared with studies performed on transgenic mice which overexpress DMPK and as a consequence develop hypertrophic cardiomyopathy, a condition which is not characteristic of DM. Importantly, there were no notable abnormalities in ex vivo ventricular hemodynamics or ECG measurements in isolated perfused hearts from DMPK overexpressor mice (32). Consequently, our results support the hypothesis that CTG expansion results in decreased DMPK protein levels, leading to key pathological changes. The present data do not preclude the possibility that partial DM locus-associated homeodomain protein (DMAHP) loss may contribute to the observed symptoms by altering transcription of other relevant proteins, such as sodium-potassium pumps or ion channel regulatory genes. As DMAHP has homology to the mouse transcription factor AREC3/six4, which regulates expression of the $\mathrm{Na}^{+} / \mathrm{K}^{+}$ATPase $\alpha 1$ subunit in developing skeletal muscle (33), it is conceivable that haploinsufficiency of DMAHP acts synergistically with DMPK loss to further alter ion homeostasis. Targeted gene disruption experiments should determine the role of partial DMAHP loss in the etiology and spectrum of DM.

In humans with DM, cardiac involvement typically manifests as conduction disturbances, with progressive deterioration in $\mathrm{A}-\mathrm{V}$ nodal and intraventricular conduction. A clinical study demonstrated progressive ECG abnormalities, with $39 \%$ of subjects developing firstdegree A-V block and 66\% demonstrating intraventricular conduction delays (34). All ECG intervals lengthened with increasing patient age, but the $\mathrm{P}-\mathrm{R}$ interval in particular had a direct correlation with age. Interestingly, the incidence of cardiac arrhythmic events (including sudden death, complete heart block, atrial fibrillation and syncope) occurred more frequently among patients with a longer baseline $\mathrm{P}-\mathrm{R}$ interval, and no correlation was seen with any other ECG interval (34). These findings suggest that the $\mathrm{P}-\mathrm{R}$ interval may be a predictive marker of patients at high risk for future arrhythmic events. Furthermore, correction of firstdegree $\mathrm{A}-\mathrm{V}$ block may prevent the development of more serious conduction disorders later in life. Similarly, in the present study, the P-R interval was prolonged in both $\mathrm{DMPK}^{-/}$and $\mathrm{DMPK}^{+/-}$adult mice, but not in younger DMPK-deficient mice, concordant with the human electrocardiographic phenotype. During in vivo electrophysiologic testing, some DMPK-/mice also had higher-grade A-V block without abnormalities in atrial or ventricular conduction properties or refractoriness. The findings from this study suggest the potential for use of the standard ECG and selected use of electrophysiologic studies when P-R prolongation is seen, for assessment of $\mathrm{A}-\mathrm{V}$ conduction in accordance with this murine DM model. Genetically manipulated DMPK mice could provide a tool for testing the efficacy of medications used to prevent heart block. DMPK replacement strategies currently being developed, similarly to dystrophin deficiency treatments, could be employed to prevent the incidence of cardiac complications related to DMPK insufficiency (35-38). This data might be extrapolated clinically for use in developing therapeutic interventional strategies for cardiac disease in myotonic dystrophy patients.

\section{Acknowledgments}

This work was supported in part by National Institutes of Health (NIH) Clinical Investigator Development Award HL-03607 (to C.I. Berul), NIH Program of Excellence grant HL-41484 (to D. Housman), and a Muscular Dystrophy Association grant (to S. Reddy). M.E. Mendelsohn is an American Heart Association Established Investigator.

1. O'Brien, T.A., and Harper, P.S. 1984. Course, prognosis and complications of childhood-onset myotonic dystrophy. Dev. Med. Child Neurol. 26:62-67.

2. Harper, P.S. 1989. Myotonic Dystrophy. 2nd ed. W.B. Saunders. London, United Kingdom.

3. Brook, J.D., et al. 1992. Molecular basis of myotonic dystrophy: expansion of a trinucleotide (CTG) repeat at the $3^{\prime}$ end of a transcript encoding a protein kinase family member. Cell. 68:799-808.

4. Fu, Y.-H., et al. 1992. An unstable triplet repeat in a gene related to myotonic muscular dystrophy. Science. 255:1256-1258.

5. Mahadevan, M., et al. 1992. Myotonic dystrophy mutation: an unstable CTG repeat in the $3^{\prime}$ untranslated region of the gene. Science. 255:1253-1255.

6. Hamshere, M.G., Newman, E.E., Alwazzan, M., Athwal, B.S., and Brook, J.D. 1997. Transcriptional abnormality in myotonic dystrophy affects DMPK but not neighboring genes. Proc. Natl. Acad. Sci. USA. 94:7394-7399.

7. Taneja, K.L., McCurrach, M.E., Shalling, M., Housman, D.E., and Singer, R.H. 1995. Foci of trinucleotide repeat transcripts in nuclei of myotonic dystrophy cells and tissues. J. Cell Biol. 128:995-1002

8. Davis, B.M., McCurrach, M.E., Taneja, K.L., Singer, R.H., and Housman, D.E. 1997. Expan- sion of a CUG trinucleotide repeat in the 3 untranslated region of myotonic dystrophy protein kinase transcripts results in nuclear retention of transcripts. Proc. Natl. Acad. Sci. USA. 94:7388-7393.

9. Klesert, T.R., Otten, A.D., Bird, T.D., and Tapscott, S.J. 1997. Trinucleotide repeat expansion at the myotonic dystrophy locus reduces expression of DMAHP. Nat. Genet. 16:402-407.

10. Thornton, C.A., Wymer, J.P., Simmons, Z., McClain, C., and Moxley, R.T., III. 1997. Expansion of the myotonic dystrophy CTG repeat reduces expression of the flanking DMAHP gene. Nat. Genet. 16:407-409.

11. Timchenko, L.T., Timchenko, N.A., Caskey, C.T., and Robert, R. 1996. Novel proteins with binding specificity for DNA CTG repeats and RNA CUG repeats: implications for myotonic dystrophy. Hum. Mol. Genet. 5:115-121.

12. Timchenko, L.T., et al. 1996. Identification of a (CUG)n triplet repeat RNA-binding protein and its expression in myotonic dystrophy. Nucl. Acids Res. 24:4407-4414.

13. Phillips, A.V., Timchenko, L.T., and Cooper, T.A 1998. Disruption of splicing regulated by CUGbinding protein in myotonic dystrophy. Science. 280:737-740.

14. Perloff, J.K., Stevenson, W.G., Roberts, N.K. Cabeen, W., and Weiss, J. 1984. Cardiac involvement in myotonic muscular dystrophy. Am.J. Cardiol. 54:1074-1081.

15. Fragola, P.V., et al. 1994. Cardiac involvement in myotonic dystrophy. Am. J. Cardiol. 74:1070-1072.

16. Litchfield, J.A. 1953. A-V dissociation in dystrophia myotonica. Br. Heart J. 15:357-359.

17. Clements, S.D., Colmers, R.A., and Hurst, W.J. 1976. Myotonia dystrophica: ventricular arrhythmias, intraventricular conduction abnormalities, atrioventricular block and Stokes-Adams attacks successfully treated with permanent transvenous pacemaker. Am. J. Cardiol. 37:933-935.

18. Prystowsky, E.N., Pritchett, E.L.C., Roses, A.D., and Gallagher, J. 1979. The natural history of conduction system disease in myotonic muscular dystrophy as determined by serial electrophysiologic studies. Circulation. 60:1360-1364.

19. Hiromaka, S., et al. 1986. A family with myotonic dystrophy associated with diffuse cardiac conduction disturbances as demonstrated by His' bundle electrocardiography. Am. Heart J 111:85-91.

20. Reddy, S., et al. 1996. Mice lacking the myotonic dystrophy protein kinase develop a late onset progressive myopathy. Nat. Genet. 13:325-335.

21. Berul, C.I., Aronovitz, M.J., Wang, P.J., and Mendelsohn, M.E. 1996. In vivo electrophysiology studies in the mouse. Circulation 94:2641-2648.

22. Berul, C.I., et al. 1997. Electrophysiological abnormalities and arrhythmias in $\alpha$ MHC mutant familial hypertrophic cardiomyopathy mice. $J$. Clin. Invest. 99:570-576.

23. Kugler, J.D. 1995. Electrophysiology studies. In Heart disease in infants, children, and adolescents, including the fetus and young adult. G.C. Emmanouilides, T.A. Reimenschneider, H.D. Allen, and H.P. Gutgesell, editors. Williams and Wilkins. Baltimore, MD. 347-366.

24. Berul, C.I., et al. 1998. Familial hypertrophic cardiomyopathy mice display gender differences in electrophysiologic abnormalities. J. Interv. Card. Electrophysiol. 2:7-14.

25. Gillette, P.C., Buckles, D.S., Harold, M., and Garson, A. 1990. Intracardiac electrophysiology studies. In Pediatric arrbythmias: electrophysiology and pacing. P.C. Gillette and A. Garson, editors. W.B. Saunders. Philadelphia, PA. 216-248.

26. Benders, A.G.M., Groenen, P.J.T.A., Oerlemans, F., Veerkamp, J.H., and Wieringa, B. 1997. Myotonic dystrophy protein kinase is involved in the modulation of the $\mathrm{Ca}^{++}$homeostasis in skeletal mus- 
cle cells. J. Clin. Invest. 100:1440-1447.

27. Chahine, M., and George, A. 1997. Myotonic dystrophy kinase modulates skeletal muscle but not cardiac voltage-gated sodium channels. FEBS Lett. 412:621-624.

28. Berul, C.I., Sweeten, T.L., Dubin, A.M., Shah, M.J., and Vetter, V.L. 1994. Use of the rate-corrected JT interval for prediction of repolarization abnormalities in children. Am. J. Cardiol. 74:1254-1257.

29. Timchenko, L.T., et al. 1995. Full-length myotonin protein kinase $(72 \mathrm{kDa})$ displays serine kinase activity. Proc. Natl. Acad. Sci. USA. 92:5366-5370.

30. Roberts, R., et al. 1997. Altered phosphorylation and intracellular distribution of a (CUG)n triplet repeat RNA-binding protein in patients with myotonic dystrophy and in myotonin protein kinase knockout mice. Proc. Natl. Acad. Sci. USA 94:13221-13226.

31. Whiting E.J., et al. 1995. Characterization of myotonic dystrophy kinase (DMK) protein in human and rodent muscle and central nervous tissue. Hum. Mol. Genet. 4:1063-1072.

32. Jansen, G., et al. 1996. Abnormal myotonic dystrophy protein kinase levels produce only mild myopathy in mice. Nat. Genet. 13:316-323.

33. Kawakami, K., Ohto, H., Ikeda, K., and Roeder, R.G. 1996. Structure, function and expression of a murine homeobox protein AREC3, a homologue of Drosophila sine oculis gene product, and implication in development. Nucleic Acids Res. 24:303-310.

34. Colleran, J.A., Hawley, R.J., Pinnow, E.E., Kokkinos, P.F., and Fletcher, R.D. 1997. Value of the electrocardiogram in determining cardiac events and mortality in myotonic dystrophy. Am. J. Cardiol. 80:1494-1497.

35. Barr, E., and Leiden, J.M. 1991. Systemic delivery of recombinant proteins by genetically modified myoblasts. Science. 254:1507-1509.

36. Gussoni, E., et al. 1992. Normal dystrophin transcripts detected in Duchenne muscular dystrophy patients after myoblast transplantation. Nature. 356:435-438.

37. Mendell, J.R., et al. 1995. Myoblast transfer in the treatment of Duchenne's muscular dystrophy. $N$ Engl. J. Med. 333:832-838.

38. Gussoni E., Blau, H.M., and Kunkel, L.M. 1997. The fate of individual myoblasts after transplantation into muscles of DMD patients. Nat. Med. 3:970-977. 